Studies on diversity and distribution of corticolous lichens as indicators of sulphur dioxide and nitrogen dioxide levels in

Colombo and suburbs

By

Attanayake Mudiyanselage Nirosha Prabhashani Attanayake

Thesis submitted to the University of Sri Jayewardenepura for the award of the Degree of Master of Philosophy in Botany on $27^{\text {th }}$ September 2006. 
"The work described in this thesis was carried out by me under the supervision of Prof. S.C. Wijeyaratne and a report on this has not been submitted in whole or in part to any university or any other institution for another Degree /Diploma".

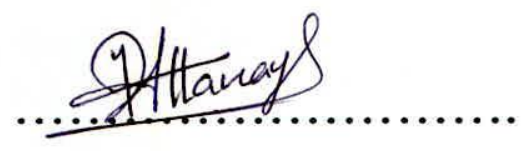

A. M. N. P. Attanayake 
"I/We certify that the above statement made by the candidate is true and that this thesis is suitable for submission to the university for the purpose of evaluation".

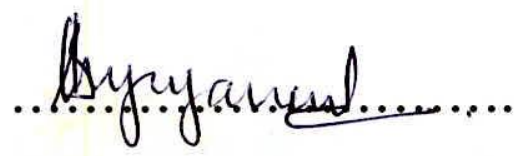

Prof. S. C. Wijeyarathne

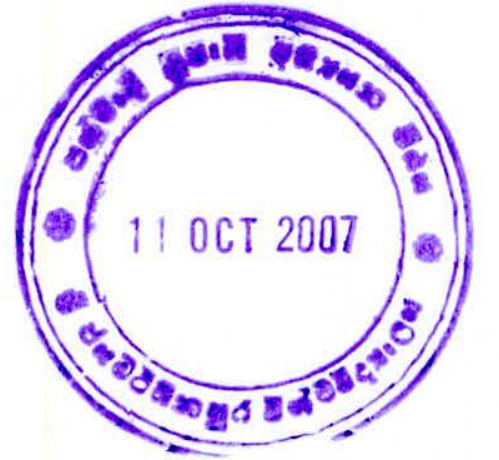




\section{CONTENTS}

List of Tables

List of figures

vii

List of plates

viii

ACKNOWLEDGEMENTS

ix

ABSTRACT

$\mathrm{xi}$

1. INTRODUCTION

2. LITERATURE REVIEW

2.1 Lichens and air pollution

2.1.1 General

2.1.2 Historical 8

2.1.3 Effect of environment on lichens

2.1.3.1 Shelter

2.1.3.2 $\mathrm{pH}$ of the substrate

2.1.3.3 Nutrients

2.1.3.4 Water relations

2.1.3.5 Age of substratum

2.1.4 General features of lichen deterioration 17

2.1.5 Causes of lichen deterioration

2.1.5.1 Background 
2.1.5.2 Effect of $\mathrm{SO}_{2}$ on lichen growth

2.1.5.3 Effect of $\mathrm{So}_{2}$ on physiology and biochemistry of lichens

2.1.5.4 Effect of nitrogen compounds on lichens

2.1.5.5 Resistance of lichens to pollution

2.1.6 Biological estimation of air pollution

2.2 Monitoring lichens 26

2.2.1 Monitoring lichens as indicators of pollution 26

2.2.2 Methods of monitoring lichens

2.2.2.1 Mapping

2.2.2.2 Index of atmospheric purity

2.2.2.3 Physiological methods

2.2.2.4 Response methods

2.2.2.5 Element bioaccumulation

2.2.2.6 Transplants

2.2.3 Some sampling method used in lichen monitoring

2.2.3.1 Lichen cover

2.2.3.2 Lichen frequency

2.2.3.3 Lichen diversity

2.3 Sulphur dioxide in the environment 40

2.4 Passive gas samplers

2.4.1 Introduction 42

2.4.2 Collection of gases 42

2.4.3 Draft shield/wind shield 43

2.4.4 Advantages of passive gas samplers 44 
2.5 Air pollution monitoring in Sri Lanka

2.5.1 Air pollution studies with respect to $\mathrm{SO}_{2}$ and $\mathrm{NO}_{2}$ conducted in Colombo area

2.5.2 Air pollution studies with respect to $\mathrm{SO}_{2}$ and $\mathrm{NO}_{2}$ air pollution in industrial areas in Sri Lanka

2.5.3 Air pollution studies with respect to $\mathrm{So}_{2}$ and $\mathrm{NO}_{2}$ air pollution in other areas in Sri Lanka

3. METHODOLOGY

3.1 Selection of study sites

\begin{tabular}{l|l|l} 
3.2 Selection of trees and registration of lichens & 56
\end{tabular}

\begin{tabular}{l|l|l}
\hline 3.3 & Identification of sites & 57
\end{tabular}

\begin{tabular}{l|r} 
3.3.1 Chemistry of thallus & 57
\end{tabular}

$\begin{array}{lr}\text { 3.3.1.1. Colour tests } & 57\end{array}$

$\begin{array}{lr}\text { 3.3.1.2 Ultra-Violet fluorescence } & 58\end{array}$

$\begin{array}{lr}\text { 3.3.1.3 Micro-cystalization } & 58\end{array}$

3.4 Determination of concentrations of $\mathrm{SO}_{2}$ and $\mathrm{NO}_{2}$ in sites $\quad 59$

$\begin{array}{ll}\text { 3.4.1 Preparation of } \mathrm{SO}_{2} \text { absorbing reagent } & 59\end{array}$

3.4.2 Preparation of Passive sampler for collecting $\mathrm{SO}_{2} \quad 59$

$\begin{array}{lll}\text { 3.4.3 Sampling of } \mathrm{SO}_{2} \text { in the atmosphere } & 61\end{array}$

\begin{tabular}{l|l|l} 
3.4.4 Analysis of $\mathrm{SO}_{2}$ & 61
\end{tabular}

\begin{tabular}{|l|l|} 
3.4.5 Preparation of the $\mathrm{NO}_{2}$ absorbing reagent & 62
\end{tabular}

3.4.6 Preparation of passive sampler for collecting $\mathrm{NO}_{2} \quad 62$

3.4.7 Sampling of $\mathrm{NO}_{2}$ in the atmosphere $\quad 62$ 
3.4.8 Analysis of $\mathrm{NO}_{2}$

3.5 Recording of land use pattern of sites

3.6 Recording of traffic densities of sites

3.7 Measuring of micro-climatic conditions

3.7.1 Measuring of bark $\mathrm{pH}$

3.7.2 Detecting exposure levels of sites to the light

3.8 Computation of lichen diversity

3.9 Statistical data analysis

66

3.10 Computation of index of atmospheric purity (IAP)

68

4. RESULTS

4.1 Identification of lichens

4.1.1 Sexual reproductive structures

4.1.2 Micro-crystallization 70

4.1.3 Identified lichens

4.1.4 Some sensitive lichens identified in the study

4.2 Summary of site data

4.3 Mean comparison of lichen diversity index

4.4 Correlation of lichen diversity index with $\mathrm{SO}_{2}$ and $\mathrm{NO}_{2}$ levels and substrate $\mathrm{pH}$

4.5 Principal Component analysis (PCA)

4.6 Distribution of sensitive lichens

4.7 Index of atmospheric purity (IAP) 


\section{DISCUSSION}

\begin{tabular}{llr}
\hline & Lichen diversity & 88
\end{tabular}

$\begin{array}{ll}5.2 & \text { Levels of pollutants }\end{array}$

$\begin{array}{lll}5.3 & \text { Mean comparison } & 91\end{array}$

$\begin{array}{lll}\text { 5.3.1 Land use pattern } & 91\end{array}$

\begin{tabular}{l|r|r}
\hline 5.3 .2 & Traffic density & 94
\end{tabular}

5.3.3 Exposure level to the light 95

5.4 Correlation between atmospheric $\mathrm{SO}_{2}, \mathrm{NO}_{2}, \mathrm{pH}$ of the substrate $\begin{array}{ll}\text { and lichen diversity } & 95\end{array}$

$\begin{array}{lll}\text { 5.5 Principal component analysis (PCA) } & 97\end{array}$

\begin{tabular}{|l|l}
5.6 & Index of Atmospheric purity (IAP)
\end{tabular}

$\begin{array}{ll}\text { 6. CONCLUSIONS } & 101\end{array}$

$\begin{array}{ll}\text { 7. REFERENCES } & 102\end{array}$

$\begin{array}{lll}\text { 8. } & \text { APPENDICES } & 114\end{array}$ 


\section{LIST OF TABLES}

Table 3.1 Descriptions of sites

$\begin{array}{lll}\text { Table } 4.1 & \text { Identified lichen genera and families. } & 71\end{array}$

Table 4.2 Summary of the result of parameters considered in the study. $\quad 74$

Table 4.3 Mean comparison for diversity index across different land use patterns in the study area.

Table 4.4 Mean comparison of lichen diversity indices across different traffic loads in the study area.

Table 4.5 Mean comparison of lichen diversity indices across different exposure levels in the study area

Table 4.6 The relationship between the lichen diversity indices

$\mathrm{SO}_{2}$ and $\mathrm{NO}_{2}$ concentrations, bark $\mathrm{pH}$ of Cocos nucifera, bark pH of Magnifera spp. and bark pH of Artocarpus heteroplyllus.

Table 4.7 The summery of the principal component analysis of eight (8) environmental parameters. 


\section{LIST OF FIGURES}

Fig: 3.1 Map of the surveyed area showing locations of 31 sites studies. 53

Fig: 3.2 Quadrate marked on tree trunk. 56

$\begin{array}{lll}\text { Fig: } 3.3 \text { Design of the passive sampler. } & 60\end{array}$

Fig: 4.1 Biplot produced by plotting the principal component 1 with principal component 2

Fig: 4.2 The trend of the changers in number of sensitive lichen taxa along six transects.

Fig: 4.3 Changers of the concentrations of $\mathrm{SO}_{2}, \mathrm{NO}_{2}$ and the IAP values along six transects. 


\section{LIST OF PLATES}

Plate 3.1 Google earth map showing six transects considered in the

study area

Plate 3.2a Passive sampler

Plate 3.2b Diffuser of passive sampler

Plate 3.3 Wind shield with the passive sampler fixed on the tree bole. 60

Plate 4.1.a Apothecia

Plate 4.1.b Perithecia

Plate 4.1.c Lirellate apothecia

Plate 4.1.d Cross section of apothecium showing spores.

Plate 4.1.e Asci with ascospores

Plate 4.2.a Micro-crystals produced by lecanoric acid with GE

Plate 4.2.b Micro crystals produced by lecanoric acid with G.A.W $\quad 70$

\begin{tabular}{l|l} 
Plate 4.3.a $\quad$ Leptogium sp. & 73
\end{tabular}

$\begin{array}{lll}\text { Plate 4.3.b Coenogonium sp. } & 73\end{array}$

$\begin{array}{lll}\text { Plate 4.3.c Roccella } \text { sp. } & 73\end{array}$

$\begin{array}{lll}\text { Plate 4.3.d Pertusaria } \text { sp. } & 73\end{array}$

$\begin{array}{lll}\text { Plate 4.3.e Parmotrema } \text { sp. } & 73\end{array}$

$\begin{array}{lll}\text { Plate 4.3.f } \quad \text { Coccocarpia } \text { sp. } & 73\end{array}$ 


\section{ACKNOWLEDGEMENTS}

This is to express my sense of gratitude to all those who have helped me to complete this research project successfully.

First of all, I wish to express my sincere thanks to Prof. S.C. Wijeyaratne, Head of the department of Botany, University of Sri Jayewardenepura, for encouraging me to do this research, for her invaluable guidance and advise, and kind cooperation rendered to me during course of this study.

I am also grateful to Prof. H.G. Nandadasa, senior professor of Botany and all the other members of the staff for giving me the opportunity to carryout this project and for the guidance.

I wish to express my sincere gratitude to Mr. Samarakkody, Mr. Premasiri and Mr. Kumari Perera of National building Research Organization for assisting me in analyzing the gaseous pollutants.

I would also wish Mr. S. Somaratne, senior lecturer, The Open University of Sri Lanka, for helping and guidance given me to do the statistical data analysis, Mr. P. Dias, senior lecturer, of the department of mathematics, and Dr. Upul Subasinghe of department of Forestry and Environmental Science, for their guidance in designing of the project.

I would like to convey my gratitude to Mr. R.M.J. Hunukumbura, and Mr. Ranjith Kandambi, Mrs. Namalee Edirisinghe and Miss Amali Wahalathanthri for giving technical assistance during this study.

My sincere thanks also go to Mr. G.F. Alwis, senior staff technician, Geography Department, for providing maps.

I would like to thank Mr. Ushan Chanaka, Mr. Bhatiya, Mr. Kosala Gunawardene, Mr. Priyantha Hemachandra, Mrs. Anuja Gunasekara and Mrs. Jeewa Wijekoon and all my other colleagues and friends who encouraged me to complete this study successfully. 
I must be thankful to Mrs. Samangi Hewage for taking photographs.

Finally I wish to express my sincere gratitude to my husband and parents who gave to moral support to complete this task successfully. 


\title{
Studies on diversity and distribution of corticolous lichens as indictors of sulphur dioxide and nitrogen dioxide levels in Colombo and suburbs
}

Attanayake Mudiyanselage Nirosha Prabhashani Attanayake

\begin{abstract}
Biological monitoring is an efficient and inexpensive method for monitoring air quality. Studies have confirmed that lichens are among the most reliable accumulators of airborne inorganic contaminants. As limited research has been done in tropics with regard to biological monitoring, a study was carried out to monitor lichen diversity and distribution in selected locations in Colombo and its suburbs.
\end{abstract}

Thirty one sites located on six radial transects diverging from Colombo Fort were selected for this study. Eight trees from three trees species, (Cocos nucifera, Mangifera spp., and Artocarpus heterophyllus) within each site $\left(1 \mathrm{~km}^{2}\right)$ were chosen for the study. Coverage and frequency of corticolous all lichens found on selected trees were recorded by using $250 \mathrm{~cm}^{2}$ grids. After studying their morphology, anatomy, reproductive structures and chemistry, lichens collected were identified using keys. In addition, land use pattern, traffic density, $\mathrm{pH}$ of substrates, exposure levels of these sites to light were also recorded. Ambient $\mathrm{SO}_{2}$ and $\mathrm{NO}_{2}$ levels at each site were determined using passive samplers having filter pads coated with the absorbing reagents, ethylene glycol and acetone, for $\mathrm{SO}_{2}$ and $\mathrm{NaI}, \mathrm{NaOH}$ and Ethylene glycol for $\mathrm{NO}_{2}$. Data were statistically analyzed by using the mean comparison, correlation and by principal component analysis to investigate relationship between diversity of lichens and environmental parameters. Index of atmospheric purity (IAP) was determined using number and frequency of each lichen species recorded at a particular site. 
Forty seven genera of lichens were identified, out of them ten genera were sensitive to air pollutants. The highest atmospheric $\mathrm{SO}_{2}$ and $\mathrm{NO}_{2}$ levels $\left(48.35 \mu \mathrm{g} / \mathrm{m}^{3}\right.$ and $\left.42.825 \mu \mathrm{g} / \mathrm{m}^{3}\right)$ as well as the lowest lichen diversity $(0.8374)$ were recorded from the site located in Colombo Fort. When land use pattern changed from village to urban and with increase of traffic density of sites, diversity of lichens reduced significantly. The relationship between diversity of lichens and levels of $\mathrm{SO}_{2}$ and $\mathrm{NO}_{2}$ was negatively correlated but significant only with levels of $\mathrm{NO}_{2}$. Further, a significant negative correlation was found between the $\mathrm{pH}$ of substrates and levels of $\mathrm{SO}_{2}$ and $\mathrm{NO}_{2}$. Principal component analysis revealed that principal component 1 (PC1), PC2 and PC3 explain 38\%, 20\% and $15 \%$ of the total variation in the data set respectively. Biplot developed by PC1 vs PC2 revealed that low lichen diversity class is clearly separated from other classes due to increased concentrations of $\mathrm{SO}_{2}, \mathrm{NO}_{2}$, land use pattern and the traffic density, all of which are included in $\mathrm{PC} 1$. Bark $\mathrm{pH}$ values of Cocos nucifera and Artocarpus heterophyllus that are represented by $\mathrm{PC} 2$ also had contributed to above grouping. Index of atmospheric purity (IAP) values increased along all transect with gradual decrease of $\mathrm{SO}_{2}$ and $\mathrm{NO}_{2}$ levels when moving away from the city. High IAP value indicates better air quality.

Absence of several pollutant sensitive tropical lichens and decrease of lichen diversity in sites with high levels of $\mathrm{SO}_{2}$ and $\mathrm{NO}_{2}$, indicate that tropical lichens have the potential to be used as indicators in air pollution monitoring work. 